\title{
English Language Proficiency Among Older Migrants in Australia, 2016-2046
}

\author{
Jeromey Temple ${ }^{1}$ (D) Tom Wilson $^{1}$ (D) $\cdot$ Bianca Brijnath $^{2}$ (D) Ariane Utomo $^{3}$ (D) \\ Peter McDonald ${ }^{1}$
}

Accepted: 5 April 2021/Published online: 11 June 2021

(C) The Author(s), under exclusive licence to Springer Nature B.V. 2021

\begin{abstract}
Australia's population is growing, ageing and exhibiting increasing heterogeneity with respect to birthplace and ethnic composition. Yet, little is understood about the levels of English language proficiency among the next generation of older migrants in Australia. Utilising a modified cohort-component model incorporating detailed language proficiency transition probabilities, we project birthplace populations by levels of English language proficiency to mid-century. Our results show that although Asian-born migrants tend to have lower levels of English proficiency, the majority of older migrants with poor proficiency are currently from a predominantly European background. In the future, we project a strong shift in the population of poor English speakers toward an Asian-born dominance as some European-born migrant groups dwindle in size and cohort flow increases population growth among older Asian migrants. Specifically, most of the population growth among older migrants with poor English proficiency occurs among Chinese and Mainland Southeast Asian migrants. However, we demonstrate that population growth among the total migrant population with poor proficiency is considerably lower than populations with good proficiency or from English-speaking households. Over the projection horizon, the total older migrant population with poor English proficiency increases by under 80,000 compared with an increase of 726,000 with good levels of proficiency and 518,000 in English-speaking households. However, we caution against conflating improved English language proficiency with a policy shift away from ethno-specific aged care services as culture, which is more than language, strongly influences perceptions of quality of aged care.
\end{abstract}

Keywords Language proficiency · Population ageing · Migrants to Australia $\cdot$ Culturally and linguistically diverse (CALD) · Ethno-specific aged care services

Jeromey Temple

jeromey.temple@unimelb.edu.au

Extended author information available on the last page of the article 


\section{Introduction}

Population ageing is projected to see the number of people aged 65 and over increase to 10 million by 2066, with just under one-quarter of the total Australian population in this age group (Wilson \& Temple, 2020). Over the same period of time, recent studies point to an increasing birthplace heterogeneity within the future Australian population (Wilson et al., 2020a; Khoo, 2012; Wilson et al., 2021). Together, these changes to Australia's future older population pose significant implications for Australian policymakers, particularly as they relate to the provision of culturally appropriate and multilingual aged care and health services (Australian Institute for Health and Welfare, 2018, 2014; Rao et al., 2006; Radermacher et al., 2009).

These demographic changes are occurring at a time when much of the demographic projection work in Australia and internationally has focused upon improving nationallevel population projections and quantifying the uncertainty of those population futures (e.g. Keilman, 2020). With a few exceptions, compositional aspects of future population change within the older population have been largely overlooked (examples of exceptions include Temple et al., 2020; Wilson et al., 2020a). This is an important omission as the Australian Aged Care Act 1997 enshrines in legislation, groups of older Australians who are considered to have special needs. Of direct relevance to this study, Section 11-3 includes people from culturally and linguistically diverse backgrounds as a population group 'with special needs'. A number of government agencies have requested improvements to data availability to help identify older Australians from culturally and linguistically diverse (CALD) backgrounds and their diverse service needs, now and in the future (see for example Australian Institute for Health and Welfare, 2014).

In this paper, we present projections of the future older population by birthplace and English language proficiency — as important measures of people from CALD backgrounds identified in the Aged Care Act. Although Australian demographic projection studies on population diversity in later life are rare, one recent study shows a significant shift in the birthplace composition of Australia's older population (Wilson et al., 2020a). To mid-century, the authors find a substantial growth of the 65+ population will occur in the coming decades, and that the overseas-born will shift from a Europeborn toward an Asia-born dominance. However, missing from this analysis was an understanding of how English language proficiency is projected to change in the future with this shift in demographic composition. Driven largely by cohort progression, understanding population growth in the numbers of older Australians with poor English language proficiency is important due to a well-documented association between language barriers, social exclusion and adverse physical and mental health outcomes among older migrants across national settings (Pot et al., 2018; Casado \& Leung, 2002; Rao et al., 2006).

\section{English Language Proficiency and Ageing}

The number of overseas-born Australians not speaking English well or not at all has risen, from around 500,000 in the period between 1991 and 2006, to about 820,000 in 2016 (about $12.6 \%$ of overseas-born population) (McDonald et al., 2019). The level of English proficiency among Australian migrant communities varies by country of 
origin, in addition to individual migrant characteristics, such as age, sex and type of visa on which they entered Australia (McDonald et al., 2019). McDonald et al.'s (2019) study highlighted several migrant groups with high levels of poor English proficiency, including, but not limited to, those born in Korea, China and Vietnam. Among the subpopulation of older migrants in Australia, populations with low-English proficiency include those of European background, including the Italian and Greek born (Australian Institute for Health and Welfare, 2018).

Studies across a range of CALD communities in Australia have documented that poor English proficiency is a risk factor for social isolation; experiencing psychological distress and anxiety; experiencing limitations in physical functions; poor access to aged care and health services; and strained family relationships (see Orb, 2002 for a review). For example, a study of Iranian-born elderly in metropolitan Sydney identified that respondents who did not speak English at home were more likely to experience psychological distress and report limitations to their physical functioning (Alizadeh-Khoei et al., 2011). Higher levels of English language proficiency in this population were associated with less anxiety and better access to health care services. In a study of older Chinese migrants in Brisbane, Ip et al. (2007) concluded that poor English proficiency-when combined with difficulty in accessing language services/interpreters-increased dependence on children. Alongside limited mobilities, the ensuing reliance on family members caused strains in the relationship with adult children (Ip et al., 2007).

In a study of language reversion among older people living with dementia, family members found it difficult to meet the care needs of their parents/grandparents when the carer themselves did not speak their parents/grandparents' first language (Tipping \& Whiteside, 2015). Haralambous et al. (2014) also highlighted how language barriers made it difficult for older Asian people with dementia and their families to access appropriate services in Melbourne. Here, health providers interviewed echoed the critical role of language in meeting the service needs of older migrants (Haralambous et al., 2014).

Language plays a key role not only in ensuring access to services, but also in fostering social networks in later life. Runci et al. (2012) compared older Australians of Greek and Italian background with dementia in ethno-specific and mainstream care facilities. They found that those residing in ethno-specific accommodation had higher rates of social resident-to-resident interaction and were prescribed fewer antipsychotic medications than those residing in mainstream care. These Australian studies outline a critical role of language in meeting the health and aged care needs of older people from CALD backgrounds. However, it should be noted that the negative effects of language barriers on the well-being of older migrants are not only confined to the context of overseas migrants in English-speaking countries like Australia. For example, in the vast linguistic landscapes of China, moving from a region with a different dialect is associated with poorer health outcomes among older internal migrants (Lu et al., 2019).

Despite the importance of language proficiency to well-being in later life, there have been few attempts to account for language composition in demographic projections. As far as we are aware, past projections with a language proficiency component have been undertaken using US data. These include projections of non-English-speaking background and limited English-proficient persons (Oxford et al., 1981) and, more recently, projections of language spoken at home (Ortman \& Shin, 2011). By understanding possible population futures for birthplace groups, disaggregated by measures of English 
proficiency, governments and aged care providers can ameliorate their planning for future service provision.

In this paper, we incorporate language proficiency into demographic projections to account for the growing heterogeneity between and within migrant groups among the older Australian population. Utilising a modified cohort-component model incorporating detailed language proficiency transition probabilities, we project birthplace populations of older Australians by levels of English language proficiency to mid-century. In the remainder of this paper, we first outline the data inputs and projection methodology. Next, we detail projections by birthplace and English language proficiency over the period 2016-2046. We conclude with a discussion of the policy relevance of our findings as well as suggesting extensions for demographic projection methods.

\section{Data and Methods}

\section{Projection Models}

Projections of the population by birthplace and English language proficiency were prepared in two stages. First, population projections by birthplace were created, and second, for all overseas-born populations, these projections were disaggregated into three English language proficiency categories:

(i) speaking English very well/well for those speaking a language other than English at home,

(ii) speaking English not well/not at all for those speaking a language other than English at home, plus

(iii) people speaking only English at home (primarily native English speakers).

The population projections were prepared by a cohort-component model specifically designed to handle multiple birthplace populations. The model is coded in VBA and incorporated into an Excel workbook which includes all the input data and projection assumptions on the future trajectories of fertility, mortality and migration, as well as detailed projection output. The heart of the model comprises a set of population accounting equations based on the movement population accounts framework (Rees, 1984; Rees \& Willekens, 1986). The model uses single year age groups and projects the population forward in single-year time intervals. Specifically, for the birthplace projection component, the procedure of Wilson et al. (2020) was followed.

For all cohorts, except the cohort born during the projection interval, the population is projected using the equation:

$$
P_{s, a+1}^{i}(t+1)=P_{s, a}^{i}(t)-D_{s, a \rightarrow a+1}^{i}+I_{s, a \rightarrow a+1}^{i}-E_{s, a \rightarrow a+1}^{i}
$$

where:

$P$ population

$D$ deaths

$I$ immigration 
$E$ emigration

$i$ birthplace

$s$ sex

$a$ age group

$t$ point in time

$t, t+1$ the one year projection interval beginning at time $t$ and ending at $t+1$

$\mathrm{a} \rightarrow \mathrm{a}+1$ the period-cohort which ages from a to a+1 during the projection interval.

For newly born babies born in Australia, the start-of-interval population in the equation above is replaced by births:

$$
P_{s, 0}^{A u s}(t+1)=B_{s}^{A u s}(t, t+1)-D_{s, b \rightarrow 0}^{A u s}+I_{s, b \rightarrow 0}^{A u s}-E_{s, b \rightarrow 0}^{A u s}
$$

where:

$B \quad$ births

Aus Australian-born

$b \rightarrow 0$ the infant period-cohort which ages from birth to age 0 during the projection interval.

For overseas-born babies, the accounting equation does not have a births term (as this population comprises babies who have migrated to Australia shortly after birth in another country):

$$
P_{s, 0}^{i}(t+1)=-D_{s, b \rightarrow 0}^{i}+I_{s, b \rightarrow 0}^{i}-E_{s, b \rightarrow 0}^{i}
$$

Emigration and deaths are calculated as the product of rates and person-years at risk, where the latter is approximated in the usual way as the mean of the start- and end-of interval populations:

$$
D_{s, a \rightarrow a+1}^{i}=d_{s, a \rightarrow a+1}^{i} \frac{1}{2}\left[P_{s, a}^{i}(t)+P_{s, a}^{i}(t+1)\right]
$$

and

$$
E_{s, a \rightarrow a+1}^{i}=e_{s, a \rightarrow a+1}^{i} \frac{1}{2}\left[P_{s, a}^{i}(t)+P_{s, a}^{i}(t+1)\right]
$$

where:

$d$ death rate

e emigration rate.

Because the projections are programmed in an iterative calculation scheme, the use of end-of-interval populations on the right-hand side of equations is unproblematic. Only for the newly born infant population is the person-years at risk term slightly different. The person-years approximation of Willekens and Drewe (1984) for low mortality populations, half the end-of-interval population, is applied. For example: 


$$
D_{s, b \rightarrow 0}^{i}=d_{s, b \rightarrow 0}^{i} \frac{1}{2}\left[P_{s, 0}^{i}(t+1)\right]
$$

Because immigration is influenced more by migration policies than origin or destination population sizes, it is projected directly as flows.

Births are projected in the usual way for a cohort-component model as the product of age-specific fertility rates and person-years at risk. The key difference is that all births from overseas-born women which occur in Australia, by definition, form part of the Australia-born population.

$$
B^{A u s}=\sum_{i} \sum_{a}\left(b_{a}^{i} \frac{1}{2}\left[P_{f, a}^{i}(t)+P_{f, a}^{i}(t+1)\right]\right)
$$

where:

$b$ fertility rate

$f$ females.

Births are then divided into males and females using the sex ratio at birth.

Projections of the overseas-born population by English language proficiency require data on transitions between English language proficiency categories, which in Australia are available in 5-year intervals. These projections were therefore prepared in 5-year intervals and 5-year age groups, and were projected using a hybrid multistate/cohort change approach because there was insufficient data to apply a fully multistate model. The projections are for persons only (not for males and females separately), and they omit the youngest $0-4$-year-old age group because language skills are still developing at these ages. The calculations proceed in three steps. First, the start-of-interval populations are subject to transitions between language categories:

$$
P_{a+5}^{i, L}(\operatorname{tmp})=P_{a}^{i, L}(t)-\sum_{K} T_{a \rightarrow a+5}^{i, L \rightarrow K}+\sum_{K} T_{a \rightarrow a+5}^{i, K \rightarrow L}
$$

where:

$L$ and $K$ language categories

$T \quad$ transition between language categories

tmp a temporary end-of-interval population prior to being subject to mortality and international migration.

The language transitions are calculated by applying a transition probability to the start-of-interval population, e.g.

$$
T_{a \rightarrow a+5}^{i, L \rightarrow K}=P_{a}^{i, L}(t) p_{a \rightarrow a+5}^{i, L \rightarrow K}
$$

where:

$p=$ transition probability.

Second, the temporary populations are summed and compared against the end-ofinterval projected population without the language disaggregation, calculated earlier. 
The discrepancy between them is due to mortality and net international migration, and is calculated as:

$$
\operatorname{Disc}_{a+5}^{i}(t+5)=P_{a+5}^{i}(t+5)-\sum_{L} P_{a+5}^{i, L}(t m p)
$$

where:

Disc discrepancy.

Third, the discrepancy is distributed across the language category populations and added to the temporary population:

$$
P_{a+5}^{i, L}(t+5)=P_{a+5}^{i, L}(t m p)+\operatorname{Disc}_{a+5}^{i}(t+5) \operatorname{Prop}_{a, a+5}^{i, L}(t, t+5)
$$

where:

Prop proportion in each language category.

The proportions are calculated differently depending on whether the discrepancy is positive or negative. Where it is positive (usually at the childhood and younger adult ages), it will be primarily due to net international migration gains. It is approximated by the distribution of English language proficiency among immigrants as measured in the latest census:

$$
\operatorname{Prop}_{a, a+5}^{i, L}(t, t+5)=\frac{I_{a, a+5}^{i, L}(t, t+5)}{\sum_{L} I_{a, a+5}^{i, L}(t, t+5)}
$$

where:

I census immigration.

If the discrepancy is negative (usually at the older adult ages where mortality dominates), then it is allocated proportionally according to the size of the temporary end-of-interval population by language group:

$$
\operatorname{Prop}_{a, a+5}^{i, L}(t, t+5)=\frac{P_{a+5}^{i, L}(t m p)}{\sum_{L} P_{a+5}^{i, L}(t m p)}
$$

Implicitly, this assumes that net losses to the population are distributed proportionally across language proficiency populations. 


\section{Input Data and Projection Assumptions}

The projections were launched from 30 June 2016 population estimates by birthplace, sex and single years of age. They were estimated by disaggregating 5 -year age group estimated resident populations (ERPs) published by the Australian Bureau of Statistics (ABS) using more detailed census data with single-year age groups. We selected birthplace groups from the ABS 'two-digit' classification which includes individual countries of birth with large populations in Australia (e.g. UK, China and India) and world regions where migrant populations from individual countries are smaller (e.g. North Africa and South America). The birthplace groups and constituent countries/ territories are listed in Table 5 in the Appendix.

Total fertility rates (TFRs) were estimated for the 2011-2016 period using ABS statistics on fertility by mother's country of birth. In the future, it is anticipated that fertility in Australia will experience a short-term reduction during the COVID-19 recession and then settle at a slightly lower level than in recent years (Wilson et al., 2021). All birthplace-specific TFRs were assumed to follow the national TFR path while maintaining the fertility differentials observed during 2011-2016.

Mortality assumptions were formulated in terms of life expectancy at birth by sex. The age-specific mortality rates required for the projection calculations were obtained by selecting rates from a national mortality surface of life table ${ }_{n} L_{x}$ values which were consistent with the assumed life expectancy values (Wilson, 2018). The mortality surface was created from a wide range of past and projected life tables for Australia, with the latter produced using Ediev's (2008) mortality forecasting method. National life expectancy at birth assumptions were obtained from the Ediev mortality forecasts. Birthplace-specific life expectancy at birth assumptions were created by assuming birthplace-specific life expectancy follows the national trajectory but with the differentials of the 2011-2016 period remaining constant.

Immigration and emigration data by sex, single years of age and country of birth for the 2011-2016 period were obtained from the ABS. Slight adjustments were made to ensure consistency in the population accounts over the 2011-2016 period, i.e. that the 2011 birthplace population for each cohort minus deaths plus immigration and minus emigration equalled the 2016 population. Assumptions were made in terms of immigration numbers and emigration rates. Over the next few years, a large drop in both immigration and emigration were assumed as the response to the COVID-19 recession and the current closure of Australia's international border. Over the longer term, emigration rates were kept constant at their 2011-2016 averages while immigration numbers were assumed to continue their gradual long-run increase.

Data for the English language proficiency projections was obtained from the 2016 Census (Australian Bureau of Statistics, 2020) and the Australian Census Longitudinal Dataset (ACLD) (Australian Bureau of Statistics, 2019). The 2016 launch populations were divided into the three language categories using 2016 Census data on language proficiency. Language category transition probabilities for the population resident in Australia were calculated from tables extracted from the ACLD, a 5\% sample of linked records from the 2011 and 2016 censuses. The language proficiency of immigrants was obtained from 2016 Census counts of immigrants arriving in Australia between 2011 and 2016. All probabilities and distributions were assumed to remain constant into the future. 


\section{Results}

Underlying the projections of English language proficiency are detailed birthplace projections for the period 2016-2046 (Table 1). There is considerable heterogeneity in the composition and growth of the older migrant population. In 2016, European-born migrants were considerably older than migrants born elsewhere, particularly Asia. For example, about half of the total populations of those born in Western, Southern or South Eastern Europe were aged 65+. The comparative figure is approximately $10 \%$ or below for most Asian regions. Presently, the population of older migrants is strongly European overall, with about $29 \%$ of older migrants in Australia born in the UK.

By 2046, we show that $18 \%$ of the older migrant population will be UK-born. Broadly, our results are consistent with an earlier Australian study, showing a strong move away from a European-born toward an Asian-born dominance in the older Australian population (Wilson et al., 2020). By 2046, migrants from Chinese Asia and Southern Asia account for $21 \%$ of the total older migrant population (increasing from $8 \%$ in 2016). Over the same period, migrants from Europe (excluding UK) fall from approximately $37 \%$ of the older population in 2016 to $12 \%$ in 2046. In addition, we also observe strong growth in the population $65+$ in the Oceanic region including in Melanesia, Micronesia and Polynesia. Although these populations age significant, they only account for a small minority of the older migrant population living in Australia.

This shift in the projected birthplace composition of Australia's older population raises the question of how this change translates into differential growth in levels of English language proficiency. Two further inputs are required for this calculation: the first of which is detailed propensities of language proficiency by age by country of birth. Figure 1 displays the estimated proportions of people reporting 'not well' levels of English proficiency by 5-year age groups. The graph begins from age 35 to 39 as this is the youngest age group considered in the $65+$ population in the year 2046. There is considerable variation in levels of poor English language proficiency by age and birthplace. Not surprisingly, levels of English proficiency are very high among English-speaking nations (e.g. New Zealand, Ireland and UK) and relatively age invariant. In contrast, many non-English-speaking countries tend to have a strong age gradient with respect to proficiency. For example, many European regions (e.g. Southern Europe and South Eastern Europe) tend to have good English proficiency in adulthood, but with poor proficiency in later life. One group of regions exhibit poor proficiency throughout the life course, but this worsens in later life (Central Asia, Chinese Asia, Mainland Southeast Asia, Japan and the Koreas).

In addition to the underlying proficiency propensities, the modelling also requires transition probabilities between English proficiency states by age and birthplace. As an example, we present census-based probabilities of proficiency transitions for the Chinese Asia-born population of Australia shown in Fig. 2. This shows that the likelihood of transitioning from good to poor English increases with rising age, while those with poor English skills are likely to improve if they are young but to a lesser extent if they are older.

Combining these input data (birthplace projections, proficiency propensities and transition probabilities), we calculate population projections by birthplace and English language proficiency to 2046 (Table 2). Table 2 presents the numbers aged $65+$ by birthplace into each language proficiency group: those speaking only English at home 


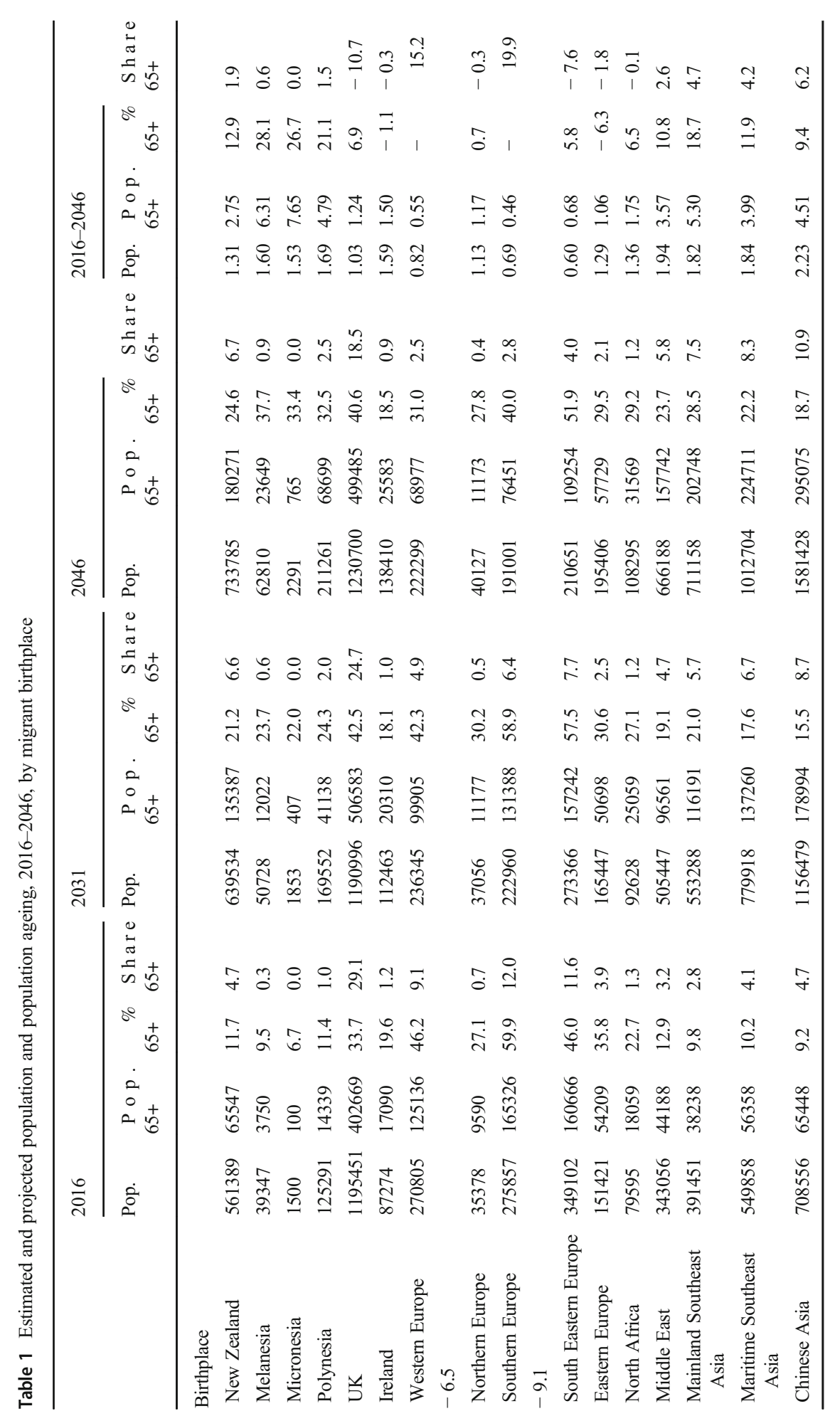




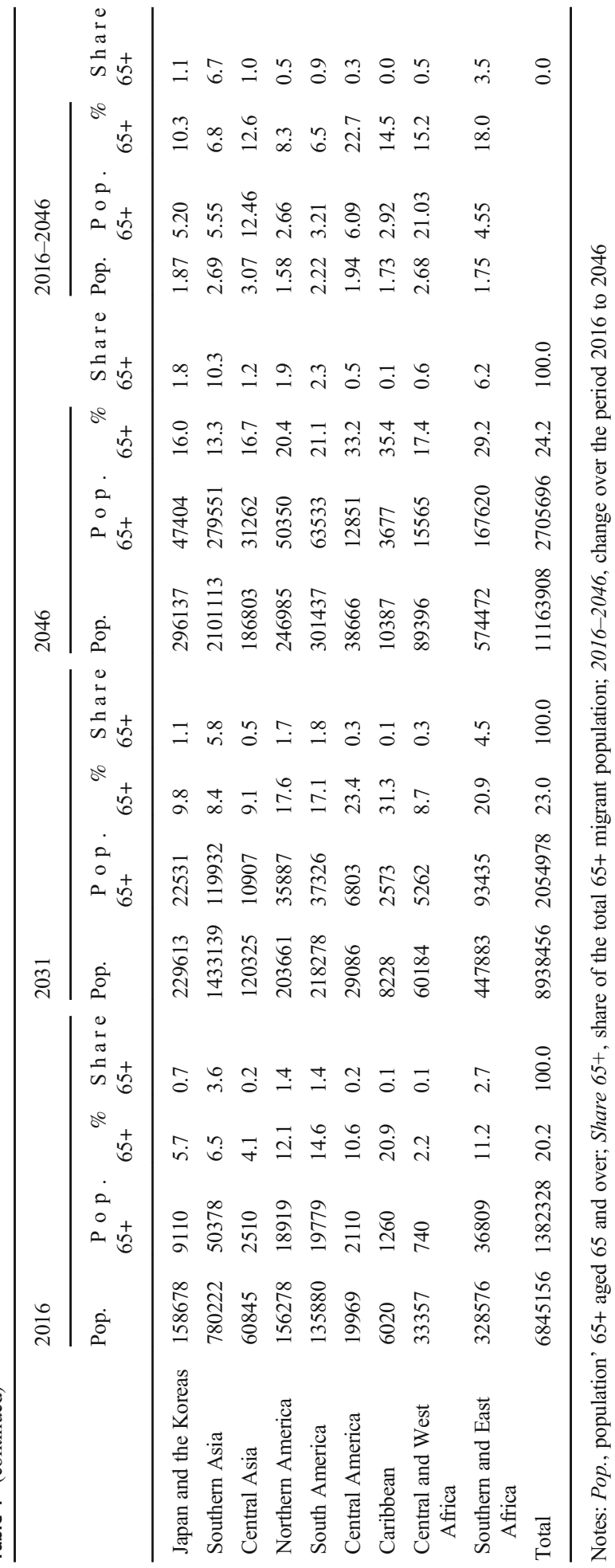




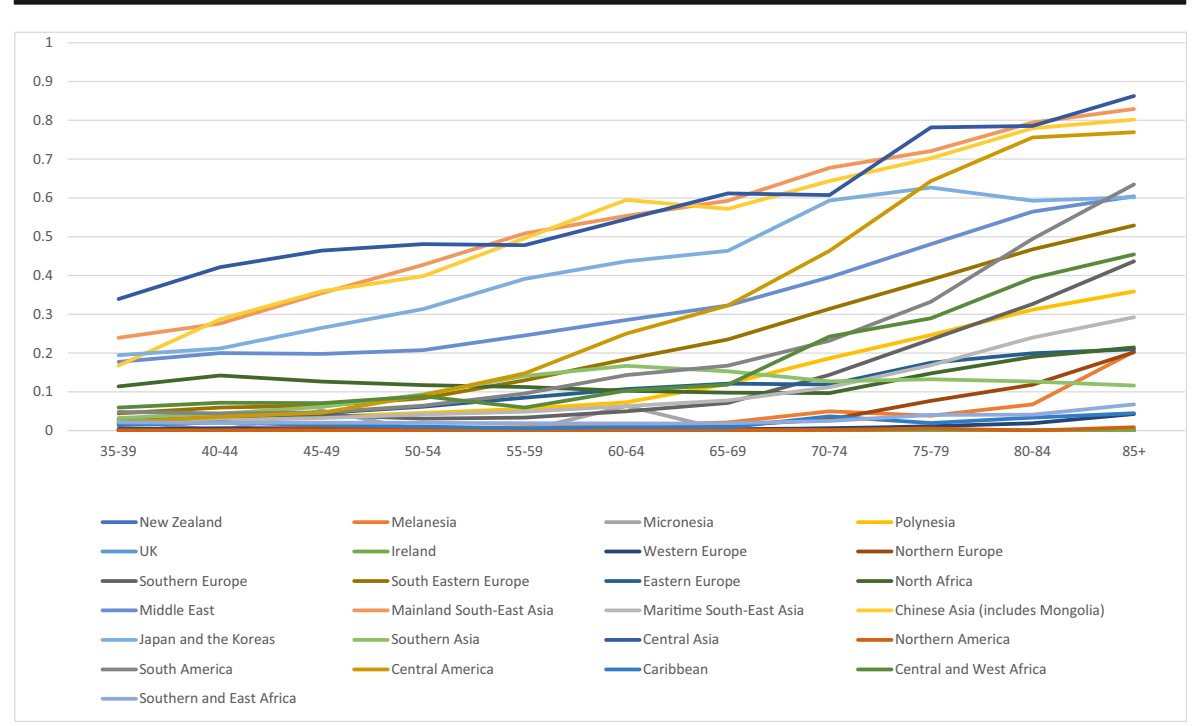

Fig. 1 Estimated proportions of people reporting 'not well' levels of English proficiency by five-year age groups, 2016

(English only), those with 'well' or 'very well' levels of proficiency (Well) and those with poor levels of proficiency including non-English speakers (Not Well). Across the full migrant population, levels of population growth (over the period 2016-2046) are higher among the 'Well' and 'English only' groups (70\% and $175 \%$ respectively), relative to those with poor English language proficiency (34\%). Specifically, in 2016, we estimate approximately 228,000 migrants with poor English proficiency, rising to 307,000 in 2046. This compares to an increase from 414,000 in 2016 to over 1.14 million migrants in 2046 speaking English well. Combining cohort differences in

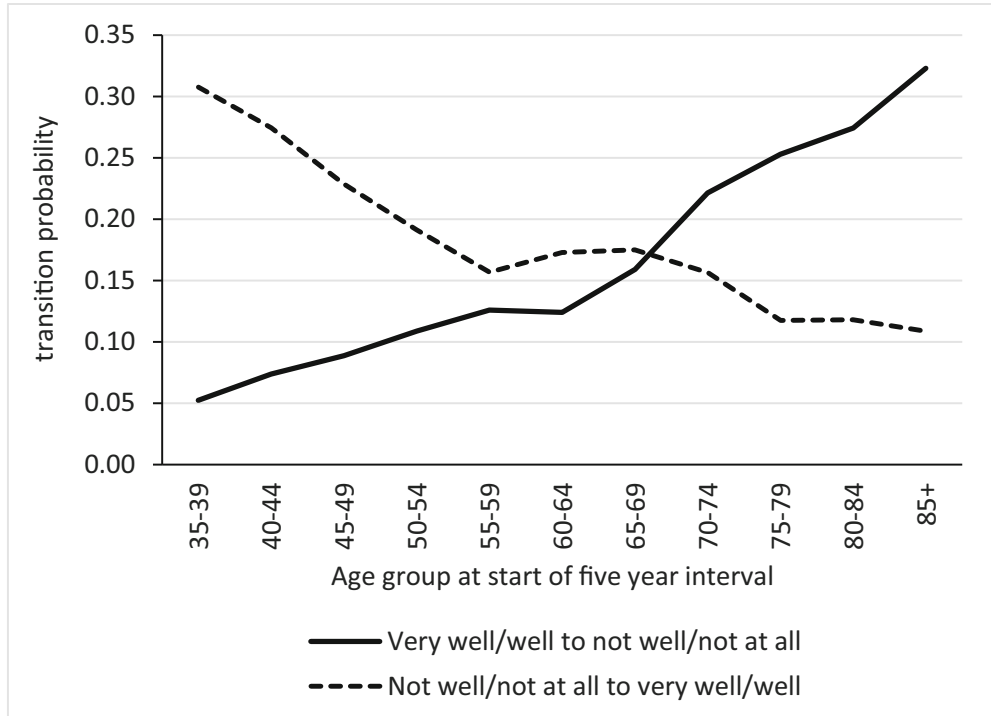

Fig. 2 English language proficiency transitions for the Chinese Asia-born, ages 15+, 2011-2016 


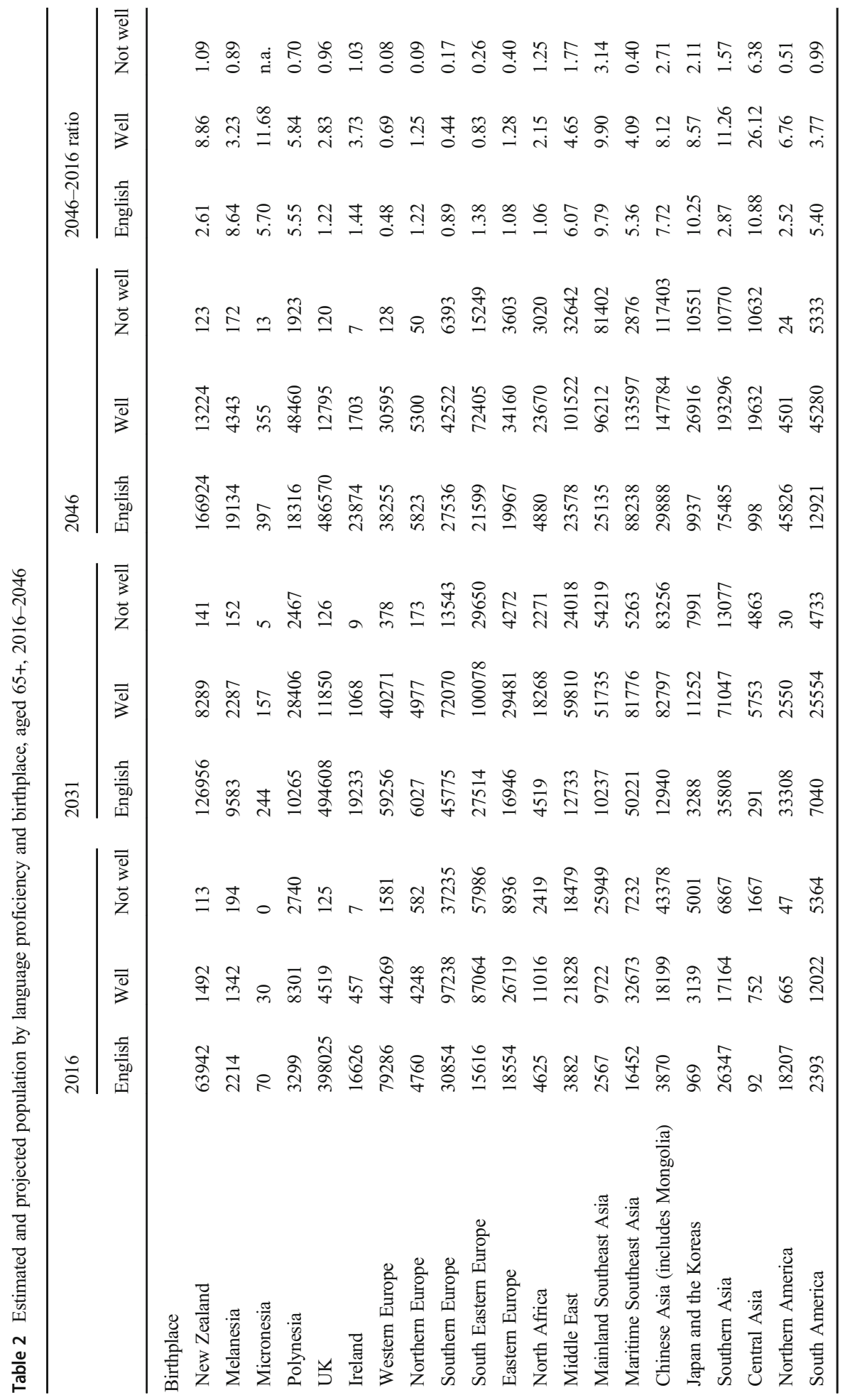




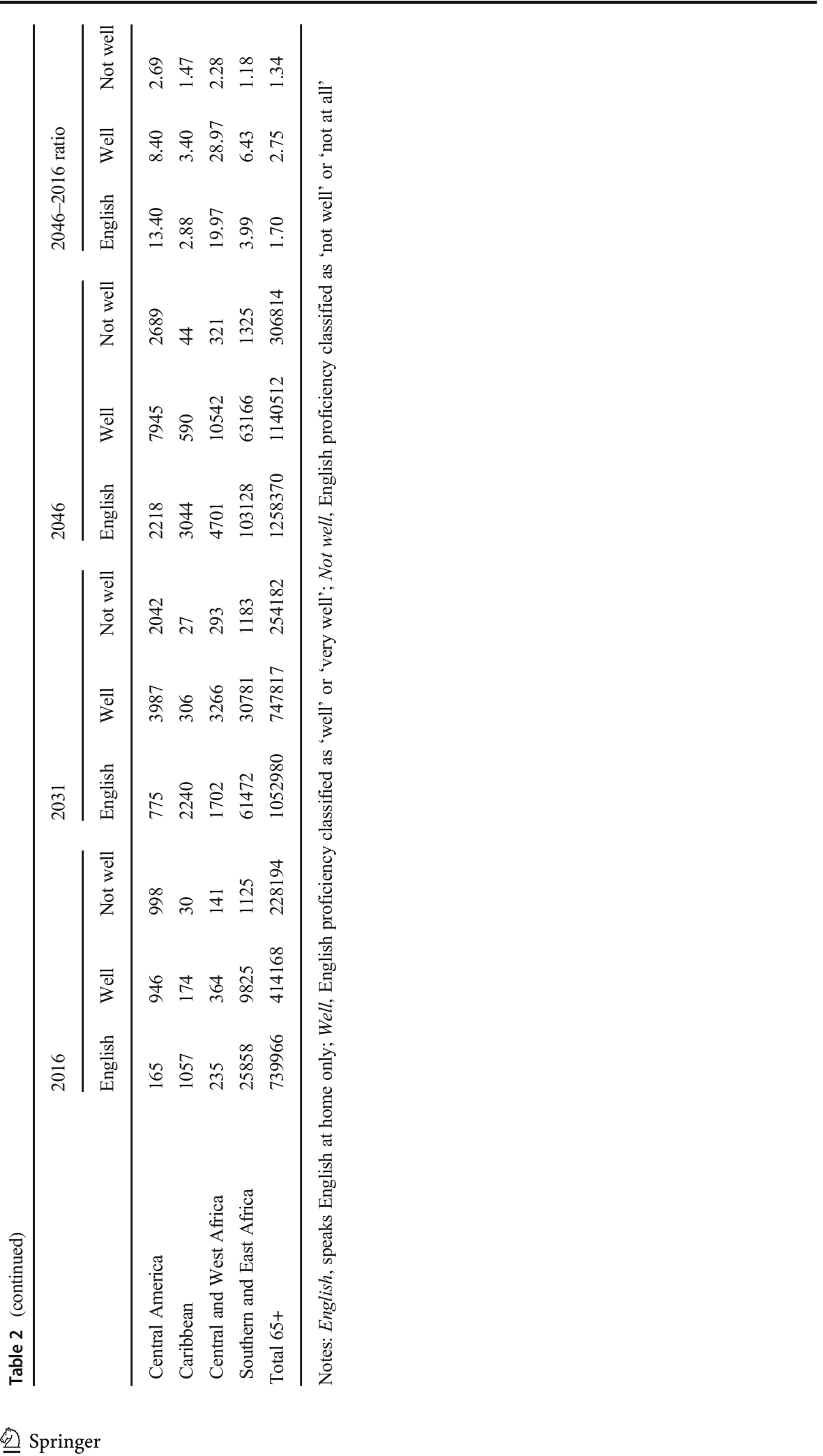


language propensities, alongside demographic change in individual countries discussed earlier, it is noteworthy that across Western, Northern, Southern, South Eastern and Eastern Europe, population growth among those older people with poor English proficiency is negative. For example, growth among those not speaking English well from South Eastern Europe is negative (- 0.26), but English-only-speaking migrants from this region experience some population growth (1.38). A number of Asian countries experience strong growth in the number of people aged 65+ with poor English language proficiency, but growth nonetheless remains stronger among the English-only speakers and those with good levels of proficiency. For example, in Chinese Asia, the number with poor levels of English proficiency increases 2.7 times by 2046 , compared with a 7 - to 8 -fold increase in the number of English speakers and those with good levels of language proficiency respectively.

The relative shifts in English language proficiency over time by birthplace are examined further in Table 3. Except for Micronesia, all birthplace groups exhibit a shift away from poor levels of English language proficiency over the projection horizon. The shifts are particularly apparent for older Asian migrants. For example, between 2016 and 2046, the proportion of older Chinese Asian migrants with poor proficiency falls by $26.5 \%$. Most of the movement away from poor proficiency is toward speaking English well $(22.3 \%)$ with the remainder accounted for an increase in English-speaking households only (4.2\%). Although some movements away from English-speaking-only across birthplaces is observed, it is only substantial in a few regions, and when it does occur, the movement is toward good levels of English proficiency, rather than poor levels. For example, among North African migrants, there is a drop of $10.2 \%$ speaking English only at home. However, there is also a $3.8 \%$ drop in the proportion with poor proficiency, with a $14 \%$ increase in the proportions speaking English well.

Given the shifts in demography, alongside significant improvements in English language proficiency among older migrants, we would expect a shift in the English proficiency distribution of the older population. Table 4 displays the projected distribution for each language proficiency level by birthplace from 2016 to 2046. Among English-speaking households only, to 2046, we project a strong movement away from persons born in the UK $(-15 \%)$, with a sizeable increase in persons born in New Zealand (4.6\%), Maritime Southeast Asia (4.8\%) and Southern Asia (2.4\%). For those speaking English well, we observe a strong shift away from the European-born (Western Europe $-8 \%$, Southern Europe (- 19.7\%), South Eastern Europe ($14.7 \%)$ ) toward the Asian-born, particularly those in Southern Asian (12.8\%), Chinese Asia (8.6\%) and Mainland Southeast Asia (6.1\%). Finally, for those with poor English proficiency, there is a strong movement away from Southern $(-14.2 \%)$ and South Eastern Europeans (-20.4\%) toward Chinese $(19.3 \%)$ and Mainland Southeast Asians (15.2\%).

Despite this strong shift toward the latter two groups, it is important to recognise that over the projection horizon, the total older migrant population with poor English proficiency increases by under 80,000 compared with an increases of 726,000 with good levels of proficiency and 518,000 in English-speaking households. In 2016, approximately $53 \%$ of older migrants resided in an English-speaking household, compared with 30\% speaking English 'well' and just under 17\% with poor English proficiency. By 2046, the proportion of older migrants with poor English proficiency 


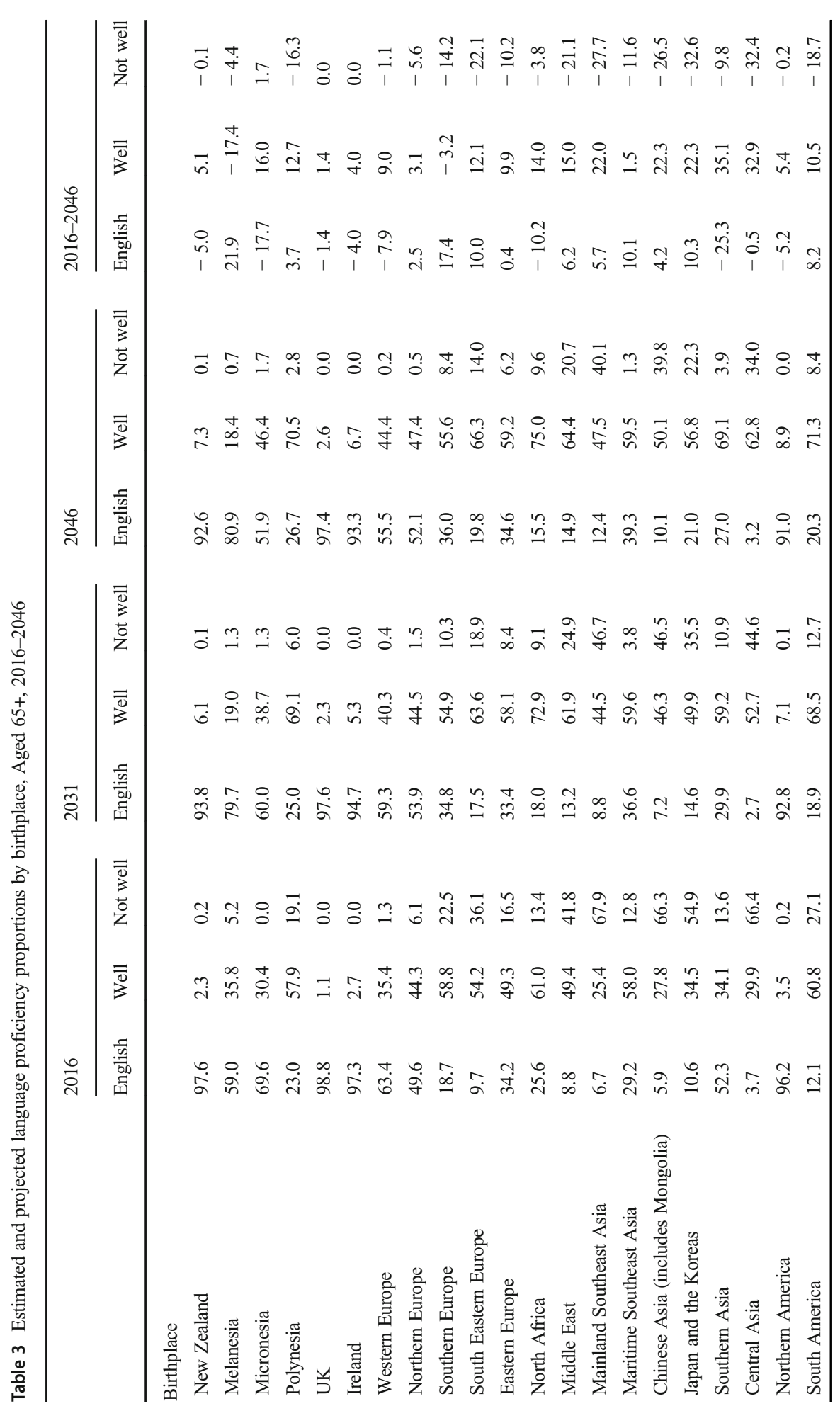




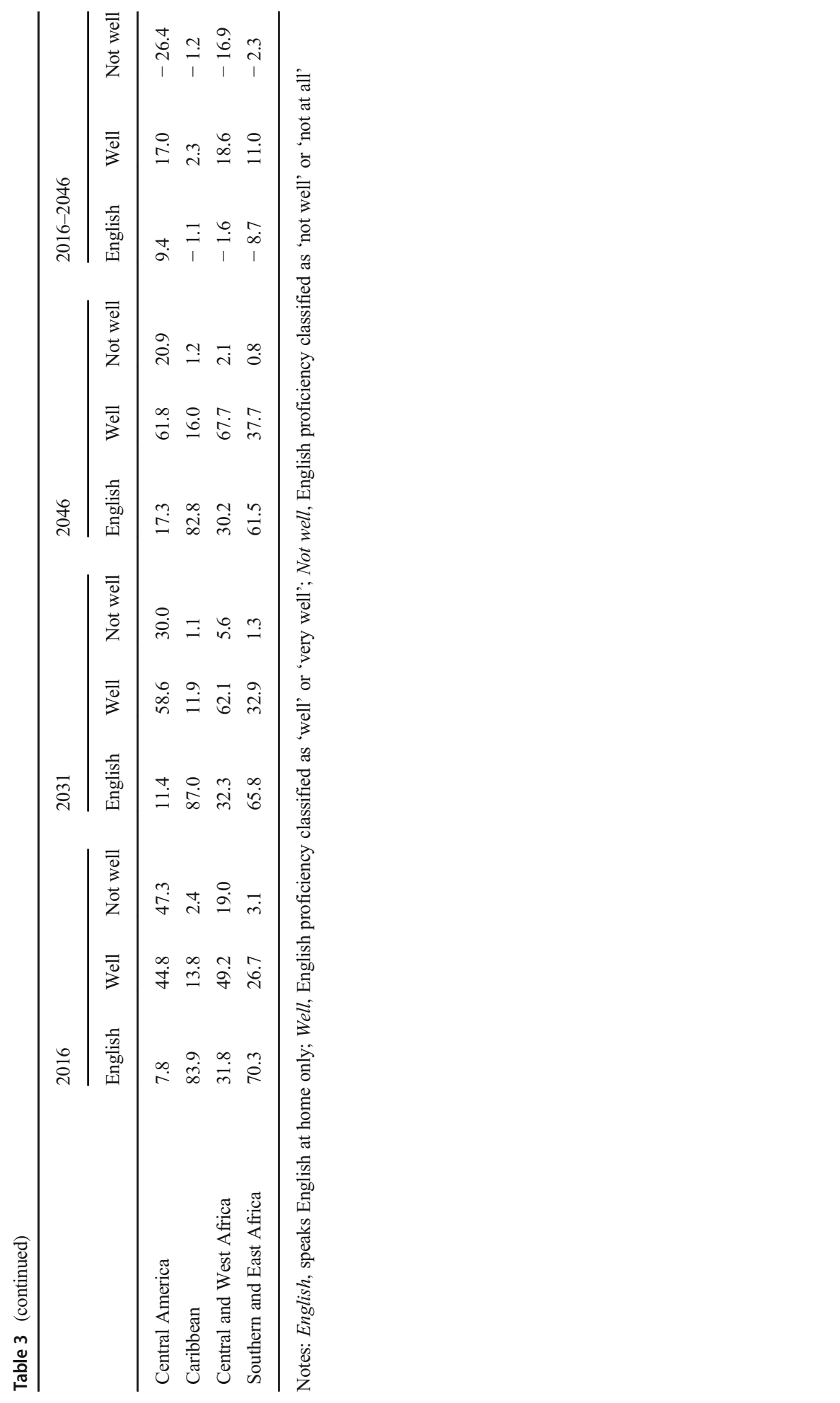




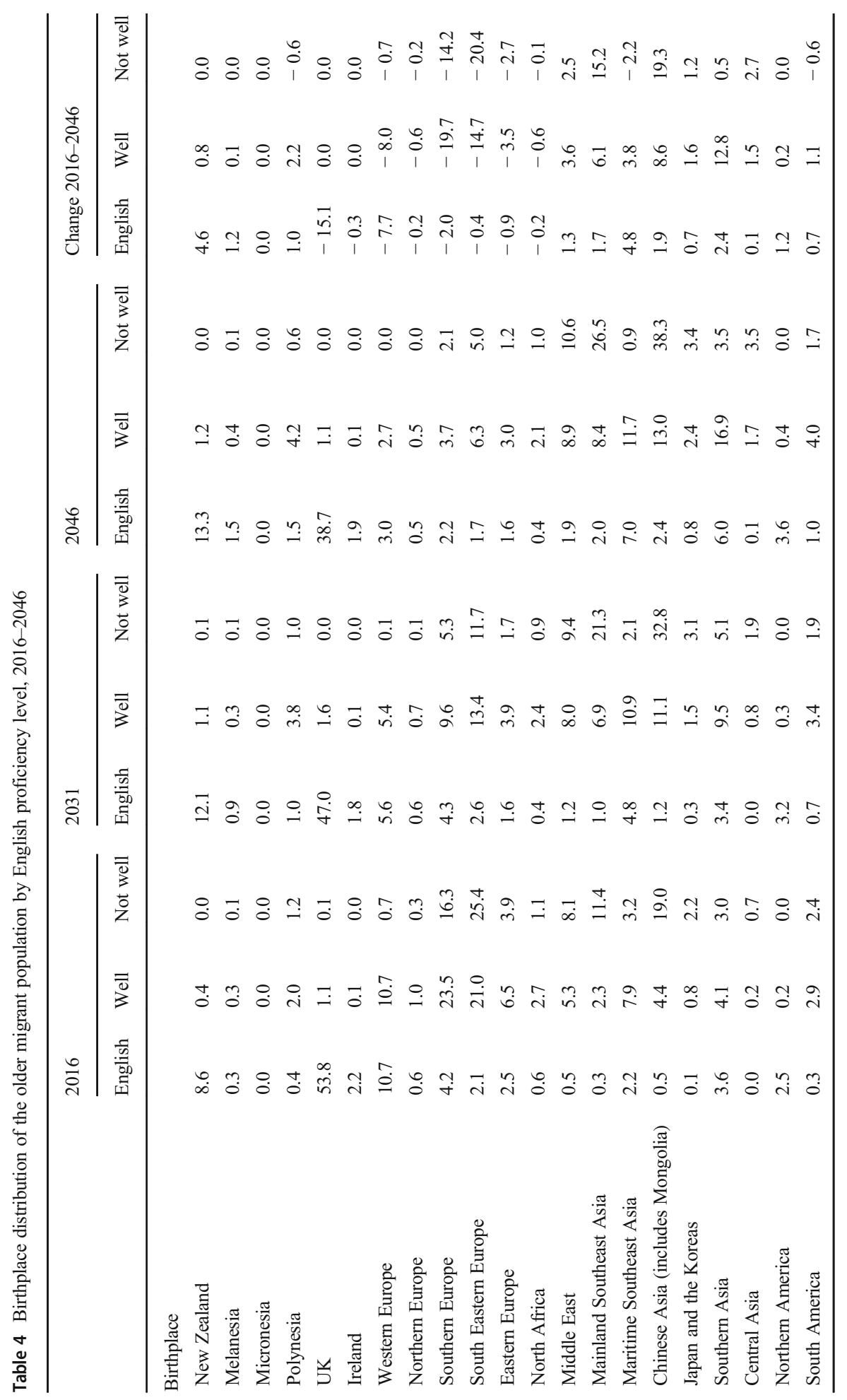




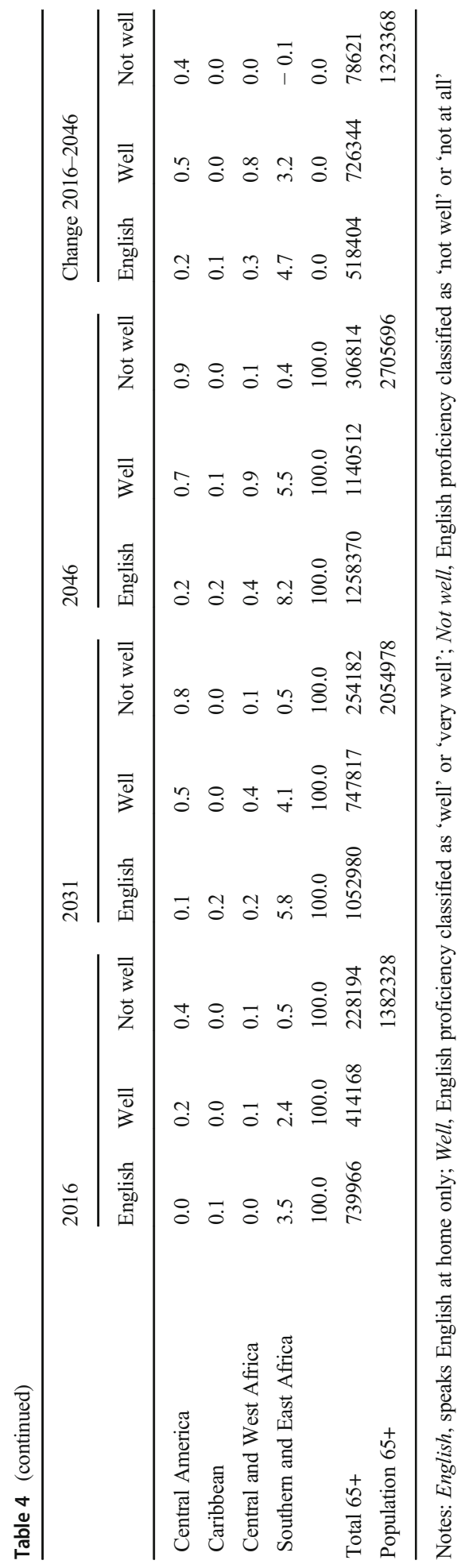


falls by just under 5 percentage points, alongside a $7 \%$ reduction in the proportion living in English-speaking-only households. This $12 \%$ difference is accounted for by an increase in the proportion of older migrants with good levels of English language proficiency.

\section{Discussion}

In the paper, we have observed that there is considerable heterogeneity in levels of language proficiency among older migrants. The current cohort of older migrants in Australia with low-English proficiency is predominantly of Italian and Greek backgrounds (Australian Institute for Health and Welfare, 2018). This is because Australia's migration policies in the 1950s and 1960s favoured the intake of low-skilled labour from Southern Europe, many of whom had low to no English proficiency, to meet the demands of Australia's growing manufacturing industries (Fanany \& Avgoulas, 2019).

However, there was a shift in immigration policy in the 1980 s to focus on recruiting a migrant labour force that could work in service-oriented and professional roles, jobs which required a higher level of English proficiency to begin with (Castles, 1992). This shift was driven by the decline in manufacturing, which disproportionately impacted migrants who experienced unemployment at two percentage points higher than Australian-born workers (Castles, 1992). As the overall unemployment rate exceeded $10 \%$ for the first time in 50 years, the government had to also deal with a burgeoning service sector, where there were few jobs for a semi-skilled to low-skilled migrant workforce with limited English proficiency (Castles, 1992). Unsurprisingly, there was a pivot in immigration policy toward skilled immigrants who were tested for their English language capability. As this cohort now ages, as revealed by our data, older migrants who speak English only at home or speak English 'well or very well' will grow by $70 \%$ and $175 \%$ respectively by 2046 .

Another reason for the increase in English proficiency among older migrants has been an overall improvement in English proficiency, including in Australia's source countries of migration which, since the 1980 s, have been mainly from Asia. Improvement in language proficiency was and is driven by globalisation and multinationalism. In Asia, especially China, the expansion of English instruction in schools has seen a rise in the population's English proficiency from low to medium (EF Education First, 2019). These overall improvements have also resulted in increasingly higher standards of proficiency and qualifications required for immigration to Australia. Such requirements apply to temporary and permanent visa holders (e.g. students and skilled workers respectively), $61.2 \%$ of whom are aged 18-34 years on arrival (Australian Bureau of Statistics, 2018). This means that as this cohort lives and works in Australia, they are likely to continue to improve (or at least maintain) their already high standard of English proficiency for many years and into later life. They are also likely to prioritise English proficiency and education in their children as has been the case for secondgeneration Greek- and Italian-Australians, both of whom are more educated and more skilled than third and subsequent generations of Australians (Messinis, 2008). While this can create a disconnect between qualification and wages as well as between skills acquired and skills needed in the job, the strong emphasis in migrant families on education highlight the importance they place on language as a determinant of labour 
market performance (Messinis, 2008). Indeed, in a recent analysis of English competency in Australia, McDonald et al. (2019), on the basis of extensive evidence relating to employment and social integration, concluded that competency in English is a necessary condition for full participation in Australian society. They also observed that the Australian school system performed well in raising the English language skills of children with poor English competency.

Our projections also highlight that population growth among the total migrant population with poor proficiency is considerably lower than populations with good proficiency or from English-speaking households. Over the projection horizon, the total older migrant population with poor English proficiency increases by under 80,000 compared with an increase of 726,000 with good levels of proficiency and 518,000 in English-speaking households. Of the 80,000 increase in the total older migrant population with poor English proficiency, most of this growth occurs among older Chinese and Mainland Southeast Asian migrants. This trend reflects the growth of Asian migrants since the 1980 s. The migrant cohorts of the 1980 s were highly segmented in the labour force, many employed as 'outworkers'-i.e. working from home-in industries such as textiles, footwear, electronics, packing and food and groceries (Castles, 1992). Now, they are entering the older age groups. Similar, to their Southern European counterparts, the nature of their work did not require much linguistic interaction in English, which may put them at a linguistic disadvantage as they age.

The ageing of Australia's overseas-born population underscores the growing demand for aged care services that account for greater language and cultural diversity. For example, the rising number of Australians living with dementia is likely to account for a marginal increase in the older migrant population with poor English proficiency. Associated with overall population ageing, dementia prevalence in Australia is anticipated to be 590,000 by 2030 (Dementia Australia, 2018). Aphasia or loss of language is a common finding in people living with dementia, and among those who are bilingual or multilingual, non-primary languages such as English may be particularly vulnerable to the effects of cognitive decline (Tipping \& Whiteside, 2015; Nickels et al., 2019). As the adage goes, 'last in-first out', a similarly, English may have been one of the later languages learned and therefore one of the first ones forgotten as dementia advances. Unfortunately, evidence on the prevalence of aphasia by birthplace using population level data is scant.

\section{Policy Implications}

The changing levels of English proficiency in older migrant populations have three main policy implications. First, our findings highlight that regardless of Australian government intervention, English proficiency is improving among new migrants partially because of baseline improvements in English in migration source countries. This is not to suggest that the Australian government should not invest in English language programs as part of settlement services. Indeed, the Australian Government, through its Adult Migrant English Program (AMEP), has recently uncapped the number of hours of English language tuition available to all new permanent residents of Australia who have less than functional English. Rather, the projections in this paper should serve as a benchmark against which the efficacy of this new policy can be tested. 
Second, despite investment in English proficiency, population ageing and a rising prevalence of dementia can undermine linguistic capacity in later life. Retreat to a primary language, often not English, is very common among first-generation bilingual and multilingual older people. As a result, there will be ongoing need for language translation and interpreting services. In addition, policies to support multilingualism and/or heritage language maintenance in migrant families may promote stronger support networks and migrants' well-being in later life, as well as foster increasingly important transnational networks for later-generation migrants.

Finally, it is insufficient to assume that the need for ethno-specific aged care services will disappear as a result of population ageing in second and third generations of migrants, who will be Australia-born and likely to have English as their primary language. Culture and language are interconnected but are not equivalent. Irrespective of English proficiency, there may be strong cultural preferences for how activities of daily life are completed and how care is delivered. For example, daily rituals and practices around personal hygiene, health and well-being, and care relationships (to name a few examples) are shaped by culture and religion (Buch, 2015). With acculturation and an acknowledgement that the nature of life in Australia is different to their countries of origin, and that traditional expectations about family care may not be possible, there may be change in attitudes toward ageing and aged care in some migrant communities (Montayre et al., 2019).

Such changes do not necessarily signal an assimilation or convergence to an Australian way of ageing or care. Recent research on aged care, health and housing revealed that one of the reasons ethno-specific organisations were able to offer integrated care within migrant communities was through their shared cultural identity and community connectedness (Gilbert et al., 2020). For these reasons, ethno-specific aged care is more than just the provision of care in the relevant language; rather, it is about offering older migrants and their families the benefits and reassurance of culturally familiar care through food, recreation activities, spiritual and religious practices, and end of life care. It is one of the main reasons why ethno-specific care is often preferred over mainstream service by older migrants, irrespective of their English language proficiency (Shanley et al., 2012).

\section{Limitations}

In interpreting results from our study, it is important to note the limitations of the underlying data, as well as the projection assumptions. Due to data limitations, we were unable to apply a fully multistate method to the projection of English language proficiency, instead having to rely on a hybrid approach. We were also only able to incorporate the effect of duration of residence in Australia on English language proficiency indirectly. We did this through the application of the language proficiency distribution of immigration flows in situations where it was necessary to add to the temporary projected population (mostly in the childhood and younger adult ages) and through the use of language proficiency transitions by age due to the approximate positive relationship between age and duration of residence. We also held language proficiency transition probabilities constant throughout the projection horizon. However, as discussed earlier, dementia and other cognitive impairments may lead 
to aphasia in later life, which in turn compromises prior gains in English proficiency. We note the important notion that English learning takes place within the family (Chiswick et al., 2005), but we were not able to account for migrants' living arrangements in our projections. Future work can account for family structure and co-ethnic residence (for example to address correlations between family members and spouses), as well as the effects of changing geographical patterns of residential segregation on English proficiency across migrant groups.

\section{Conclusion}

English language proficiency is a key determinant of positive social and economic outcomes for Australian migrants. Not only crucial to gaining employment, income and hours worked (Cobb-Clark, 2000; Khoo \& McDonald, 2003; Law, 2011), proficiency in English is also important in alleviating social exclusion and loneliness through reduction in language barriers (Joint Standing Committee on Migration, 2013). However, to date, there has been a paucity of studies examining futures of migrant ageing and proficiency in the settlement country's main language.

In addressing this gap, focusing on English proficiency among older Australian migrants, our results highlight a significant shift in the projected birthplace populations by levels of English proficiency to mid-century. In the future, we project a strong shift in the population of poor English speakers toward an Asian-born dominance as some European-born migrant groups dwindle in size and cohort flow increases population growth among older Asian migrants. In particular, most of the growth in older migrants with poor English proficiency occurs among Chinese and Mainland Southeast Asian migrants. However, we demonstrate that population growth among the total migrant population with poor proficiency is considerably lower than populations with good proficiency or from English-speaking households. Taken together, these results highlight shifting linguistic capabilities in future cohorts of Australia's migrant population.

For these reasons, it is important to ensure English language proficiency in migrants across the life course, including into later life. The Australian Government has recently made a policy announcement to provide subsidised English language courses to migrants including older migrants. Upskilling older migrant's English skills increases their social and economic participation, whether as family carers, health and care consumers, and/or paid workers. It is also important not to conflate improved English language proficiency with a policy shift away from ethno-specific aged care services. Culturally appropriate care embodies much more than service delivered in a relevant language. Rather, such care speaks to the influence of migration, culture, history and transnationalism on attitudes toward ageing and care. Where conditions such as dementia further compromise English linguistic capacity, it is important for the appropriate services to support older people and their families. These are two good reasons why special arrangements will still be necessary for older migrants into the future. 


\section{Appendix}

Table 5 Country of birth categories

\begin{tabular}{|c|c|}
\hline Country/region & Constituent countries/territories \\
\hline Australia & Australia \\
\hline New Zealand & New Zealand \\
\hline Melanesia & New Caledonia, Papua New Guinea, Solomon Islands, Vanuatu \\
\hline Micronesia & $\begin{array}{l}\text { Guam, Kiribati, Marshall Islands, Federated States of Micronesia, Nauru, } \\
\text { Northern Mariana Islands, Palau }\end{array}$ \\
\hline Polynesia & $\begin{array}{l}\text { Cook Islands, Fiji, French Polynesia, Niue, Samoa, American Samoa, Tokelau, } \\
\text { Tonga, Tuvalu, Wallis and Futuna, Pitcairn Islands }\end{array}$ \\
\hline UK & UK, Channel Islands, Isle of Man \\
\hline Ireland & Ireland \\
\hline Western Europe & $\begin{array}{l}\text { Austria, Belgium, France, Germany, Liechtenstein, Luxembourg, Monaco, } \\
\text { Netherlands, Switzerland }\end{array}$ \\
\hline Northern Europe & $\begin{array}{l}\text { Denmark, Faroe Islands, Finland, Greenland, Iceland, Norway, Sweden, Aland } \\
\text { Islands }\end{array}$ \\
\hline Southern Europe & Andorra, Gibraltar, Holy See, Italy, Malta, Portugal, San Marino, Spain \\
\hline South Eastern Europe & $\begin{array}{l}\text { Albania, Bosnia and Herzegovina, Bulgaria, Croatia, Cyprus, North Macedonia, } \\
\text { Greece, Moldova, Romania, Slovenia, Montenegro, Serbia, Kosovo }\end{array}$ \\
\hline Eastern Europe & $\begin{array}{l}\text { Belarus, Czech Republic, Estonia, Hungary, Latvia, Lithuania, Poland, Russian } \\
\text { Federation, Slovakia, Ukraine }\end{array}$ \\
\hline North Africa & $\begin{array}{l}\text { Algeria, Egypt, Libya, Morocco, Sudan, Tunisia, Western Sahara, Spanish North } \\
\text { Africa, South Sudan }\end{array}$ \\
\hline Middle East & $\begin{array}{c}\text { Bahrain, Gaza Strip and West Bank, Iran, Iraq, Israel, Jordan, Kuwait, Lebanon, } \\
\text { Oman, Qatar, Saudi Arabia, Syria, Turkey, United Arab Emirates, Yemen }\end{array}$ \\
\hline Mainland Southeast Asia & Myanmar, Cambodia, Laos, Thailand, Vietnam \\
\hline Maritime Southeast Asia & Brunei Darussalam, Indonesia, Malaysia, Philippines, Singapore, Timor-Leste \\
\hline Chinese Asia & $\begin{array}{l}\text { China (excludes SARs and Taiwan), Hong Kong (SAR of China), Macau (SAR } \\
\text { of China), Mongolia, Taiwan }\end{array}$ \\
\hline Japan and the Koreas & $\begin{array}{l}\text { Japan, Democratic People's Republic of Korea (North), Republic of Korea } \\
\text { (South) }\end{array}$ \\
\hline Southern Asia & Bangladesh, Bhutan, India, Maldives, Nepal, Pakistan, Sri Lanka \\
\hline Central Asia & $\begin{array}{l}\text { Afghanistan, Armenia, Azerbaijan, Georgia, Kazakhstan, Kyrgyzstan, Tajikistan, } \\
\text { Turkmenistan, Uzbekistan }\end{array}$ \\
\hline North America & Bermuda, Canada, St Pierre and Miquelon, United States of America \\
\hline South America & $\begin{array}{l}\text { Argentina, Bolivia, Brazil, Chile, Colombia, Ecuador, Falkland Islands, French } \\
\text { Guiana, Guyana, Paraguay, Peru, Suriname, Uruguay, Venezuela }\end{array}$ \\
\hline Central America & $\begin{array}{l}\text { Belize, Costa Rica, El Salvador, Guatemala, Honduras, Mexico, Nicaragua, } \\
\text { Panama }\end{array}$ \\
\hline Caribbean & $\begin{array}{l}\text { Anguilla, Antigua and Barbuda, Aruba, Bahamas, Barbados, Cayman Islands, } \\
\text { Cuba, Dominica, Dominican Republic, Grenada, Guadeloupe, Haiti, Jamaica, } \\
\text { Martinique, Montserrat, Puerto Rico, St Kitts and Nevis, St Lucia, St Vincent } \\
\text { and the Grenadines, Trinidad and Tobago, Turks and Caicos Islands, British } \\
\text { Virgin Islands, United States Virgin Islands, St Barthelemy, St Martin (French } \\
\text { part), Bonaire, Sint Eustatius and Saba, Curacao, Sint Maarten (Dutch part) }\end{array}$ \\
\hline
\end{tabular}


Table 5 (continued)

\begin{tabular}{|c|c|}
\hline Country/region & Constituent countries/territories \\
\hline Central and West Africa & $\begin{array}{l}\text { Benin, Burkina Faso, Cameroon, Cabo Verde, Central African Republic, Chad, } \\
\text { Republic of Congo, Democratic Republic of Congo, Cote d'Ivoire, Equatorial } \\
\text { Guinea, Gabon, Gambia, Ghana, Guinea, Guinea-Bissau, Liberia, Mali, } \\
\text { Mauritania, Niger, Nigeria, Sao Tome and Principe, Senegal, Sierra Leone, } \\
\text { Togo }\end{array}$ \\
\hline Southern and East Africa & $\begin{array}{l}\text { Angola, Botswana, Burundi, Comoros, Djibouti, Eritrea, Ethiopia, Kenya, } \\
\text { Lesotho, Madagascar, Malawi, Mauritius, Mayotte, Mozambique, Namibia, } \\
\text { Reunion, Rwanda, St Helena, Seychelles, Somalia, South Africa, Swaziland, } \\
\text { Tanzania, Uganda, Zambia, Zimbabwe }\end{array}$ \\
\hline
\end{tabular}

Source: https:/www.abs.gov.au/ausstats/abs@.nsf/Lookup/2901.0Chapter1102016

\section{References}

Alizadeh-Khoei, M., Mathews, R. M., \& Hossain, S. Z. (2011). The role of acculturation in health status and utilization of health services among the Iranian elderly in metropolitan Sydney. Journal of Cross-Cultural Gerontology, 26(4), 397-405. https://doi.org/10.1007/s10823-011-9152-z.

Australian Bureau of Statistics. (2018). 3101.0 - Australian demographic statistics, June 2018. Feature article 2: Spotlight on net overseas migration. https://www.abs.gov.au/ausstats/abs@.nsf/ featurearticlesbyCatalogue/7A40A407211F35F4CA257A2200120EAA?OpenDocument\#: :text=The\% 20majority $\% 20$ of $\% 20$ migrants $\% 20$ to,for\%20departures $\% 20$ was $\% 2027.9 \% 20$ years.

Australian Bureau of Statistics. (2019). Microdata: Australian census longitudinal dataset, ACLD. Catalogue No. 2080.0. https://www.abs.gov.au/AUSSTATS/abs@.nsf/Lookup/2080.0Main+Features1ACLD

Australian Bureau of Statistics. (2020). ABS Tablebuilder. https://www.abs.gov.au/websitedbs/censushome. nsf/home/tablebuilder. Accessed 26 March 2020.

Australian Institute for Health and Welfare. (2014). Cultural and linguistic diversity measures in aged care. AIHW https://www.aihw.gov.au/getmedia/8ea33339-11fd-4f3a-b452-4636d282d480/17698.pdf.aspx? inline $=$ true.

Australian Institute for Health and Welfare. (2018). Older Australia at a glance https://www.aihw.gov.au/ reports/older-people/older-australia-at-a-glance/contents/demographics-of-older-australians/australia-schanging-age-and-gender-profile.

Buch, E. D. (2015). Anthropology of aging and care. Annual Review of Anthropology, 44(1), 277-293. https:// doi.org/10.1146/annurev-anthro-102214-014254.

Casado, B. L., \& Leung, P. (2002). Migratory grief and depression among Elderly Chinese American immigrants. Journal of Gerontological Social Work, 36(1-2), 5-26. https://doi.org/10.1300/ J083v36n01_02.

Castles, S. (1992). The 'new' migration and Australian immigration policy. In C. Ingils, G. S, G. Sullivan, \& C.-T. Wu (Eds.), Asians in Australia: The dynamics of migration and settlement (pp. 45-72). Singapore: .

Chiswick, B. R., Lee, Y. L., \& Miller, P. W. (2005). Parents and children talk: English language proficiency within immigrant families. Review of Economics of the Household, 3(3), 243-268. https://doi.org/10. 1007/s11150-005-3457-z.

Cobb-Clark, D. A. (2000). Do selection criteria make a difference?: Visa category and the labour market status of immigrants to Australia. Economic Record, 76(232), 15-31. https://doi.org/10.1111/j.1475-4932.2000. tb00002.x.

Dementia Australia. (2018). Dementia prevalence data 2018-2058, commissioned research undertaken by NATSEM, University of Canberra. https:/www.dementia.org.au/information/statistics/prevalence-data

Ediev, D. M. (2008). Extrapolative projections of mortality: Towards a more consistent method part I: The central scenario. Vienna Institute of Demography Working Papers. https:/www.oeaw.ac.at/fileadmin/ subsites/Institute/VID/PDF/Publications/Working_Papers/WP2008_03.pdf

EF Education First. (2019). EF English proficiency index: A ranking of 100 countries and regions by English skills. https:/www.ef.com/_/ /media/centralefcom/epi/downloads/full-reports/v9/efepi-2019-english.pdf 
Fanany, R., \& Avgoulas, M.-I. (2019). Greek identity in Australia. In S. Ratuva (Ed.), The Palgrave Handbook of Ethnicity (pp. 1-18). Springer Singapore.

Gilbert, A. S., Owusu-Addo, E., Feldman, P., Mackell, P., Garratt, S. M., \& Brijnath, B. (2020). Models of integrated care, health and housing: Report prepared for the Royal Commission into Aged Care Quality and Safety. National Ageing Research Institute.

Haralambous, B., Dow, B., Tinney, J., Lin, X., Blackberry, I., Rayner, V., Lee, S. M., Vrantsidis, F., Lautenschlager, N., \& LoGiudice, D. (2014). Help seeking in older Asian people with dementia in Melbourne: Using the Cultural Exchange Model to explore barriers and enablers. Journal of CrossCultural Gerontology, 29(1), 69-86. https://doi.org/10.1007/s10823-014-9222-0.

Ip, D., Lui, C. W., \& Chui, W. H. (2007). Veiled entrapment: a study of social isolation of older Chinese migrants in Brisbane, Queensland. Ageing and Society, 27(5), 719-738. https://doi.org/10.1017/ S0144686X07006083.

Joint Standing Committee on Migration. (2013). Inquiry into migration and multiculturalism in Australia. Canberra The Parliament of the Commonwealth of Australia.

Keilman, N. (2020). Uncertainty in population forecasts for the twenty-first century. Annual Review of Resource Economics, 12(1), 449-470. https://doi.org/10.1146/annurev-resource-110319-114841.

Khoo, S.-E. (2012). Ethnic disparities in social and economic well-being of the immigrant aged in Australia. Journal of Population Research, 29(2), 119-140.

Khoo, S.-E., \& McDonald, P. (2003). The transformation of Australia's population: 1970-2030. UNSW Press.

Law, V. (2011). English proficiency and labour supply of Immigrants in Australia. Crawford School Research Paper, 12 .

Lu, S., Chen, S., \& Wang, P. (2019). Language barriers and health status of elderly migrants: Micro-evidence from China. China Economic Review, 54, 94-112. https://doi.org/10.1016/j.chieco.2018.10.011.

McDonald, P., Moyle, H., \& Temple, J. (2019). English proficiency in Australia, 1981 to 2016. Australian Journal of Social Issues, 54(2), 112-134. https://doi.org/10.1002/ajs4.67.

Messinis, G. (2008). Overeducation and overskilling in Australia: Second generation Greek-Australians and Italian-Australians. In V. U. Centre for Strategic Economic Studies (Ed.), Working Paper No. 37. Melbourne. https://vises.org.au/documents/wp37.pdf

Montayre, J., Neville, S., Wright-St Clair, V., Holroyd, E., \& Adams, J. (2019). Older Filipino immigrants' reconfiguration of traditional filial expectations: A focus ethnographic study. Contemporary Nurse, 56, 113. https://doi.org/10.1080/10376178.2019.1640621.

Nickels, L., Hameau, S., Nair, V. K. K., Barr, P., \& Biedermann, B. (2019). Ageing with bilingualism: Benefits and challenges. Speech, Language and Hearing, 22(1), 32-50. https://doi.org/10.1080/ 2050571X.2018.1555988.

Orb, A. (2002). Health care needs of elderly migrants from culturally and linguistically diverse (CALD) backgrounds: A review of the literature.

Ortman, J. M., \& Shin, H. B. (2011). Language projections: 2010 to 2020. In American Sociological Association Annual Meeting.

Oxford, R., Pol, L., Lopez, D., Stupp, P., Gendeil, M., \& Peng, S. (1981). Projections of non-English language background and limited English proficient persons in the United States to the year 2000: Educational planning in the demographic context. NABE Journal, 5(3), 1-30. https://doi.org/10.1080/08855072.1981. 10668408 .

Pot, A., Keijzer, M., \& De Bot, K. (2018). The language barrier in migrant aging. International Journal of Bilingual Education and Bilingualism, 1-19. https://doi.org/10.1080/13670050.2018.1435627.

Radermacher, H., Feldman, S., \& Browning, C. (2009). Mainstream versus ethno-specific community aged care services: It's not an 'either or'. Australasian Journal on Ageing, 28(2), 58-63. https://doi.org/10. 1111/j.1741-6612.2008.00342.x.

Rao, D. V., Warburton, J., \& Bartlett, H. (2006). Health and social needs of older Australians from culturally and linguistically diverse backgrounds: Issues and implications. Australasian Journal on Ageing, 25(4), 174-179. https://doi.org/10.1111/j.1741-6612.2006.00181.x.

Rees, P. (1984). Spatial population analysis using movement data and accounting methods: Theory, models, the 'MOVE' program and examples. In Working paper 404: School of Geography. University of.

Rees, P., \& Willekens, F. (1986). Data and accounts. In A. Rogers \& F. J. Willekens (Eds.), Migration and settlement: A multiregional comparative study. (pp. 19-58.). Dordrecht: D. Reidel.

Runci, S., Eppingstall, B., \& O’Connor, D. W. (2012). A comparison of verbal communication and psychiatric medication use by Greek and Italian residents with dementia in Australian ethno-specific and mainstream aged care facilities. International Psychogeriatrics, 24(5), 733-741. 
Shanley, C., Boughtwood, D., Adams, J., Santalucia, Y., Kyriazopoulos, H., Pond, D., \& Rowland, J. (2012). A qualitative study into the use of formal services for dementia by carers from culturally and linguistically diverse (CALD) communities. BMC Health Services Research, 12(1), 354. https://doi.org/10.1186/14726963-12-354.

Temple, J. B., Wilson, T., Taylor, A., Kelaher, M., \& Eades, S. (2020). Ageing of the Aboriginal and Torres Strait Islander population: Numerical, structural, timing and spatial aspects. Australian and New Zealand Journal of Public Health, 44(4), 271-278. https://doi.org/10.1111/1753-6405.13001.

Tipping, S. A., \& Whiteside, M. (2015). Language reversion among people with dementia from culturally and linguistically diverse backgrounds: The family experience. Australian Social Work, 68(2), 184-197. https://doi.org/10.1080/0312407X.2014.953187.

Willekens, F. J., \& Drewe, P. (1984). A multiregional model for regional demographic projection. In H. Heide \& F. J. Willekens (Eds.), Demographic research and spatial policy: The Dutch experience (pp. 309-334). Academic Press.

Wilson, T. (2018). Evaluation of simple methods for regional mortality forecasts. Genus, 74(1), 14. https://doi. org/10.1186/s41118-018-0040-z.

Wilson, T., \& Temple, J. (2020). To what extent is Australia's population ageing? The application of traditional and alternative ageing measures. Australian Population Studies, 4(1), 57-69.

Wilson, T., McDonald, P., Temple, J., Brijnath, B., \& Utomo, A. (2020). Past and projected growth of Australia's older migrant populations. Genus, 76(20), 20.

Wilson, T., Temple, J., \& Charles-Edwards, E. (2021). How might the COVID-19 pandemic affect population ageing in Australia?. Journal of Population Research. https://doi.org/10.1007/s12546-021-09255-3.

Wilson, T., Temple, J., Brijnath, B., McDonald, P., \& Utomo, A. (2021). Projections of older European migrant populations in Australia, 2016-56. Journal of Population Ageing. https://doi.org/10.1007/ s12062-020-09319-x.

Publisher's Note Springer Nature remains neutral with regard to jurisdictional claims in published maps and institutional affiliations.

\section{Affiliations}

\section{Jeromey Temple ${ }^{1} \cdot$ Tom Wilson $^{1} \cdot$ Bianca Brijnath $^{2} \cdot$ Ariane Utomo $^{3} \cdot$ Peter McDonald $^{1}$}

1 Demography and Ageing Unit, Melbourne School of Population and Global Health, University of Melbourne, 207 Bouverie St, Melbourne, Victoria 3010, Australia

2 National Ageing Research Institute (NARI), Melbourne, Australia

3 School of Geography, Faculty of Science, University of Melbourne, Melbourne, Australia 